\title{
Hepatocellular carcinoma and type 2 diabetes mellitus: two cases highlighting changes in tumor glycogen content
}

\author{
Kunio Takegoshi ${ }^{1}$, Eikichi Okada ${ }^{2}$, Kazuhiro Nomoto ${ }^{3}$, Kouji Nobata ${ }^{4}$, \\ Takuro Sawasaki ${ }^{5}$, Mitsuhiro Terada ${ }^{5}$, Hirofumi Terakawa ${ }^{6}$, Takashi Kobayashi ${ }^{6}$, \\ Kazuhisa Yabushita ${ }^{6}$, Tatsuho Sugimoto ${ }^{7}$, Shintaro Terahata ${ }^{8}$
}

${ }^{1}$ Takegoshi Internal Medicine Clinic, 377-7 Nomura, Takaoka, Toyama 933-0014, Japan

${ }^{2}$ Pathological Division of Takaoka City Hospital, 4-1 Takara-machi, Takaoka, Toyama 933-8550, Japan

${ }^{3}$ Pathological Division of Kouseiren Takaoka Hospital, 5-10 Eirakucho, Takaoka, Toyama 933-8555, Japan

${ }^{4}$ Radiological Division of Kouseiren Takaoka Hospital, 5-10 Eirakucho, Takaoka, Toyama 933-8555, Japan

${ }^{5}$ Gastroenterological Division of Kouseiren Takaoka Hospital, 5-10 Eirakucho, Takaoka, Toyama 933-8555, Japan

${ }^{6}$ Surgical Division of Takaoka City Hospital, 4-1 Takara-machi, Takaoka, Toyama 933-8550, Japan

${ }^{7}$ Gastroenterological Division of Kanazawa Seirei Hospital, 1 Chome-5-30 Nagamachi, Kanazawa, Ishikawa 920-0865, Japan

${ }^{8}$ Pathological Division of Tonami General Hospital, 1-61 Shintomi-cho, Tonami, Toyama 939-1395, Japan

\begin{abstract}
This article reports two patients with hepatocellular carcinoma (HCC) and type 2 diabetes mellitus (T2DM), who showed marked changes in hepatocellular glycogen content. Periodic acid-Schiff (PAS)-positive and diastase-PAS-negative (glycogen-storing) hepatocytes were detected in both background liver parenchyma and in HCC tissues. In HCC tissues, the number of glycogen-storing cells resembling hepatocytes was considerably reduced and unevenly distributed as compared with hepatocytes in background liver. To be known, changes in hepatocellular glycogen content in T2DM patients have not been previously described. It is hypothesized that the reduction in glycogen content in both patients was likely associated with the emergence of Warburg type of glycolysis.
\end{abstract}

Key words: Glycogen; hepatocellular carcinoma; hexokinase II; steatohepatitis; type 2 diabetes mellitus

Address for correspondence:

Dr. Kunio Takegoshi, Takegoshi Internal Medicine Clinic, 377-7 Nomura, Takaoka, Toyama 933-0014, Japan. E-mail: kunio@takegoshi.jp

Received: 10-04-2015, Accepted: 06-09-2015

\section{INTRODUCTION}

Most cases of hepatocellular carcinoma (HCC) occur in patients with chronic liver disease and advanced fibrosis. Well-known causes of chronic liver disease leading to HCC include chronic hepatitis B virus (HBV) and hepatitis C virus infection, ${ }^{[1]}$ chronic alcohol abuse ${ }^{[1,2]}$ and more recently, non-alcoholic fatty liver disease (NAFLD) ${ }^{[3]}$ In addition, type 2 diabetes mellitus (T2DM) has been

\begin{tabular}{|l|l|}
\hline \multicolumn{3}{|c|}{ Access this article online } \\
\hline \multirow{2}{*}{$\begin{array}{l}\text { Website: } \\
\text { http://hr.oaepublish.com/ }\end{array}$} \\
\hline
\end{tabular}

associated with HCC. ${ }^{[4]}$ Patients with T2DM and NAFLDrelated non-cirrhotic or cirrhotic livers may develop HCC, suggesting a role for T2DM in hepatocarcinogenesis. ${ }^{[3]}$

Glycogen loading of the liver was first documented as a component of Mauriac's syndrome in 1930, and

This is an open access article distributed under the terms of the Creative Commons Attribution-NonCommercial-ShareAlike 3.0 License, which allows others to remix, tweak, and build upon the work non-commercially, as long as the author is credited and the new creations are licensed under the identical terms.

For reprints contact: service@oaepublish.com

How to cite this article: Takegoshi K, Okada E, Nomoto K, Nobata K, Sawasaki T, Terada M, Terakawa H, Kobayashi T, Yabushita K, Sugimoto T, Terahata S. Hepatocellular carcinoma and type 2 diabetes mellitus: two cases highlighting changes in tumor glycogen content. Hepatoma Res 2016;2:26-30. 
enhanced glycogen deposits were observed with increasing frequency in patients with brittle diabetes. ${ }^{[5,6]}$ Excessive storage of glycogen [glycogen-storing foci (GSF)] has been observed in pre-neoplastic foci of altered hepatocytes (FAH), and in highly differentiated subpopulations of benign and malignant hepatocellular lesions in animal models of hepatocarcinogenesis. ${ }^{[-9]}$ Glycogenotic cells (clear cell) have been observed in liver biopsies and explants from the patients harboring foci and nodules of altered hepatocytes. ${ }^{[10,11]}$ Although clear cell HCCs have been described, their glycogen content was usually not determined. ${ }^{[12]}$

To our knowledge, there have been no comparative studies on changes in hepatocellular glycogen content of HCC and background livers in patients with T2DM. This study describes two patients with HCC and T2DM, who showed marked changes in hepatocellular glycogen content.

\section{CASE REPORT}

\section{Case 1}

A 72-year-old Japanese man with T2DM and alcoholic liver disease was diagnosed with HCC by computed tomography (CT) examination. Laboratory data showed aspartate transaminase (AST) $95 \mathrm{IU} / \mathrm{L}$, alanine transaminase (ALT) $65 \mathrm{IU} / \mathrm{L}$, alpha-fetoprotein (AFP) $8.2 \mathrm{ng} / \mathrm{mL}$, protein-induced by vitamin $\mathrm{K}$ absence factor II (PIVKA-II) $26 \mathrm{mAU} / \mathrm{mL}$, fasting blood sugar (FBS) $228 \mathrm{mg} / \mathrm{dL}$, and hemoglobin A1c (HbA1c) 7.9\%. CT arterial portography and CT hepatic arteriography revealed 2 minor nodules $(3-4 \mathrm{~mm})$ at $\mathrm{S} 5$, and a larger nodule $(2.5 \mathrm{~cm} \times 2.3 \mathrm{~cm})$ at $\mathrm{S} 8$.

A specimen, obtained from needle biopsy of the S8 tumor, was fixed with Carnoy's solution, and formalin for a routine histological diagnosis. Samples were stained with periodic acid-Schiff (PAS) and PAS after diastase pretreatment (D-PAS). Hexokinase II (HK-II) was detected immunohistochemically using anti-HK II (C64G5) rabbit mAb (Cell Signaling Technology, Inc. Danvers, US). HK-II

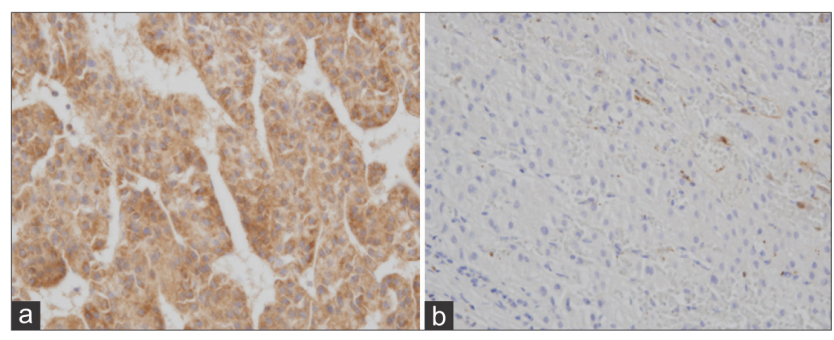

Figure 1: Control - hexokinase II activity in hepatocellular carcinoma tissues (a) and background liver (b) of positive control (65-year-old male, welldifferentiated adenocarcinoma in background of chronic hepatitis $\mathrm{C}$ ) ( $\mathrm{a}$ and $\mathrm{b}$ : hexokinase II, $\times 400$ ) activity in positive control was also indicated [Figure 1a and $b]$.

Histologic examination showed a well- to moderatelydifferentiated HCC [Figure 2a], with the background liver showing steatohepatitis with alcoholic pericellular fibrosis [Figure 2b]. Both PAS-positive [Figure 2c and d] and D-PAS-negative (glycogen-storing) hepatocytes [Figure 2e and $\mathrm{f}$ ] were detected in the background liver and in HCC tissues. However, the PAS-positive hepatocytes were more abundant in the background liver than in the HCC tissues. No pronounced clear cells were detected. HK-II expression was weak in HCC [Figure $2 \mathrm{~g}$ ] and faint in background liver [Figure $2 \mathrm{~h}$ ]. Clinical and pathological data are summarized in Table 1.

\section{Case 2}

A 73-year-old Japanese man with T2DM and nonalcoholic steatohepatitis (NASH) was diagnosed with HCC by CT examination. At the age of 64 , he was diagnosed with T2DM and NASH via needle biopsy of the liver. Laboratory examination showed AST 51 IU/L, ALT 22 IU/L, AFP 4.4 ng/mL, PIVKA-II 22 mAU/mL, FBS 140 mg/ $\mathrm{dL}$, and $\mathrm{HbA1c} 6.3 \%$.

Partially, hepatectomized liver tissue was fixed as described in Case 1. Macroscopically, the HCC was revealed as simple nodular type (size, $1.8 \mathrm{~cm} \times 1.5$ $\mathrm{cm}$; stage 1, T1NOM0; Child-Pugh grade A). Histological examination showed a well-differentiated HCC [Figure 3a], with the background liver presenting as type B cirrhosis [Figure 3b]. PAS-positive [Figure $3 \mathrm{c}$ and d] and D-PAS-negative [Figure $3 e$ and $\mathrm{f}$ ] hepatocytes were detected in both background liver and in HCC tissues, although the PAS-positive hepatocytes were more abundant in background liver than in the tumors. HKII was weakly expressed in HCC [Figure 3g] and faintly expressed in background liver [Figure 3h]. No obvious clear cells were detected.

\section{DISCUSSION}

This study describes the two patients with T2DM, who developed HCC. Background liver in both patients showed steatohepatitis, suggesting that HCC may have been mainly due to steatohepatitis. The alcohol intake may have been a risk factor for HCC in Case $1,^{[2]}$ whereas occult HBV infection with positivity for hepatitis B surface anti-body/hepatitis B core anti-body may have been a risk factor in Case 2. ${ }^{[13]}$

Glycogenotic hepatocytes are a common preneoplastic liver lesion in human at a high risk of HCC development. ${ }^{[11,14]} \mathrm{FAH}$, including GSF, was detected in 
Table 1: Summary of clinical and pathological data

\begin{tabular}{|c|c|c|}
\hline & Case 1 & Case 2 \\
\hline Age/gender & 72 years/male & 73 years $/$ male \\
\hline DM type/duration & $2 / 16$ years & $2 / 9$ years \\
\hline Insulin level & $3.5 \mu U / m L$ & $20.1 \mu \mathrm{U} / \mathrm{mL}$ \\
\hline Body mass index (kg/m2) & 20.8 & 22.1 \\
\hline Alcohol & $63 \mathrm{~g} /$ day, 40 years & \\
\hline $\mathrm{HBsAg} / \mathrm{cAb} / \mathrm{sAb} / \mathrm{HCV}$ & $-1-1-1-$ & $-/+/+/-$ \\
\hline $\begin{array}{l}\text { Biopsy or resection } \\
\text { HCC }\end{array}$ & Needle biopsy & Partial resection \\
\hline \multirow[t]{2}{*}{ Size (location) } & $2.5 \mathrm{~cm} \times 2.3 \mathrm{~cm} \mathrm{(S8)}$ & $1.8 \mathrm{~cm} \times 1.5 \mathrm{~cm}(\mathrm{~S} 8)$ \\
\hline & (3-4) $\mathrm{mm} \times(3-4) \mathrm{mm}$, double (S5) & \\
\hline Histology & Well- to moderately-differentiated adenocarcinoma & Well-differentiated adenocarcinoma \\
\hline PAS-positive cells diastase-PAS & Small numbers negative & Uneven negative \\
\hline HK-II immunostaining & Weak positive & Weak positive \\
\hline \multicolumn{3}{|l|}{ Background liver } \\
\hline Histology & Steatohepatitis with pericellular brosis (F2-3) & Liver cirrhosis, type B NASH (9 years ago) \\
\hline PAS-positive cells diastase-PAS & Abundant numbers negative & Abundant numbers negative \\
\hline HK-II immunostaining & Faint positive & Faint positive \\
\hline
\end{tabular}

DM: diabetes mellitus; HBsAg: hepatitis B surface antigen; cAb: core anti-body; sAb: surface anti-body; HCV: hepatitis C virus; HCC: hepatocellular carcinoma; PAS: periodic acid-Schiff; HK-II: hexokinase II; NASH: non-alcoholic steatohepatitis

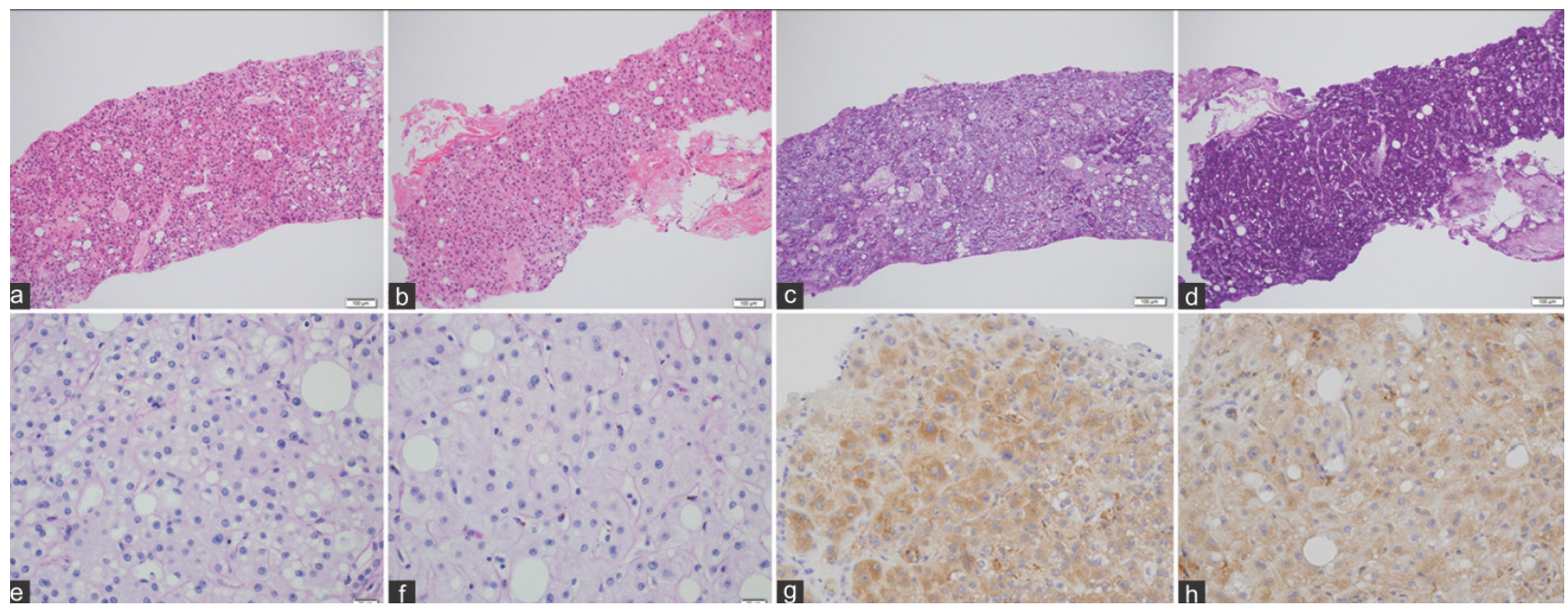

Figure 2: Case 1-histochemical comparison of glycogen content and hexokinase II activity in hepatocellular carcinoma tissues (a, c, e, and g) and background liver (b, d, f, and h) (a and b: HE, ×100; c and d: periodic acid-Schiff, $\times 100$; e and f: diastase-periodic acid-Schiff, $\times 100 ; \mathrm{g}$ and $\mathrm{h}$ : hexokinase II, $\times 400$ )

84 of $111(75.7 \%)$ patients with cirrhotic liver diseases, with a higher incidence in patients HCC than those without HCC. ${ }^{[11]}$ GSF were also detected in a significant number of human non-cirrhotic livers (88 of 236; 33.6\%). ${ }^{[15]}$ A combination of enzymatic and molecular biological approaches has shown the striking similarities in metabolic changes in human and rat GSF, including the activation of the AKT/mammalian target of rapamycin (mTOR) and Ras/MAPK signaling cascades. ${ }^{[15]}$

Studies in more than 150 human explants showed the evidence for a characteristic sequence of cellular changes, from pre-neoplastic glycogenotic FAH via various intermediate stages [mixed cell foci (MCF)] to glycogen-poor malignant phenotypes, similar to that in animal models. ${ }^{[9,11]}$ These phenotypic cellular changes are due to a metabolic switch from gluconeogenesis toward the pentose phosphate pathway and the Warburg type of glycolysis. ${ }^{[9,11]}$ In human $\mathrm{HBV}$-associated tumorigenesis, the mTOR signaling cascade has been shown to play a crucial role in driving the metabolic alterations toward increased aerobic glycolysis. ${ }^{[16]}$ When initial excess glycogen stores are reduced, the storage of polysaccharides is often largely replaced by the accumulation of neutral lipids. ${ }^{[17]}$ In both of our patients, PAS-positive/DPAS-negative hepatocytes, which store glycogen albeit not the excessive amounts, were detected in background livers and HCC tissues. Hepatocytes rich in glycogen were abundant in background liver parenchyma but were mixed with glycogen-poor cells in HCC tissues. Neither pronounced clear cells nor MCF were detected. Fat deposits were rare in HCC tissues and background livers of both of these patients.

Changes in glycogen content frequently accompany a shift in the expression of isoenzymes during progression, e.g., from low-affinity (glucokinase/ HK IV) to high affinity (HK-II) HK, ${ }^{[17,18]}$ HK-II being characteristic of Warburg type of glycolysis occurring in rapidly growing tumors, including HCC. ${ }^{[17,19]}$ 

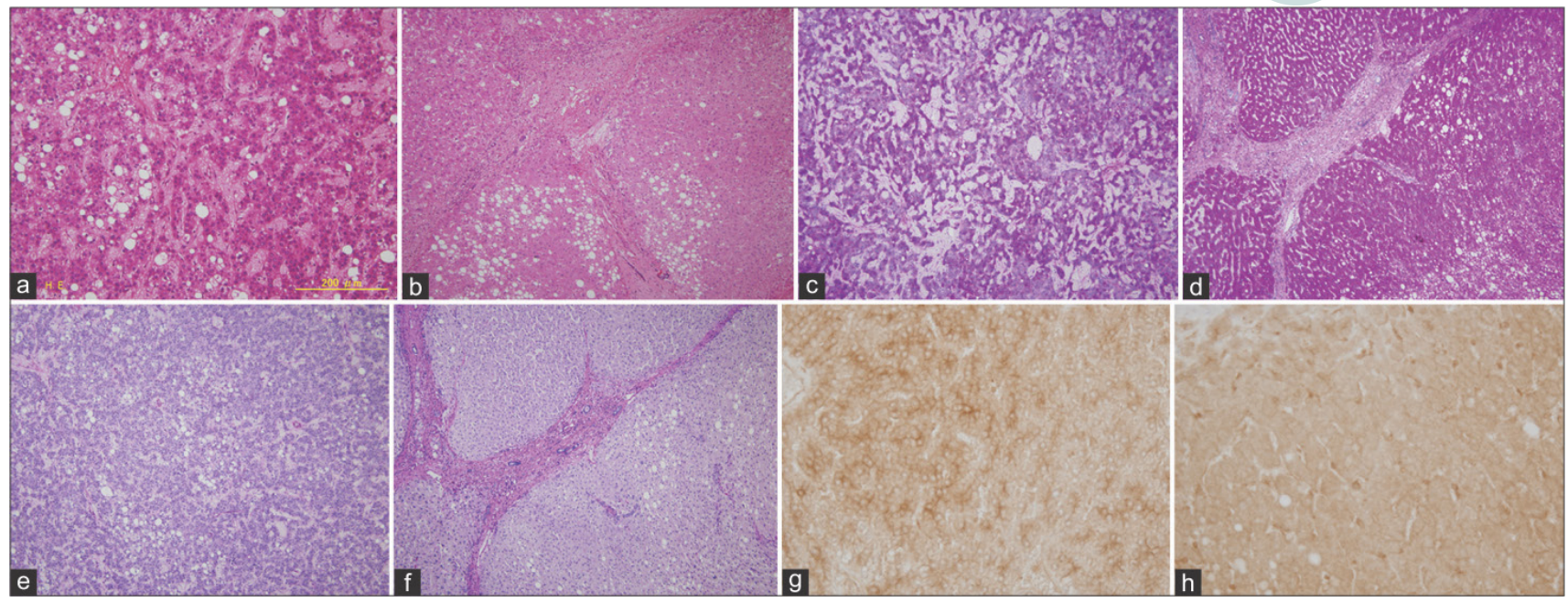

Figure 3: Case 2 - histochemical comparison of glycogen content and hexokinase II activity in hepatocellular carcinoma tissues (a, c, e, and g) and background liver (b, d, f, and h) (a and b: HE, ×100; c and d: periodic acid-Schiff, ×100; e and f: diastase-periodic acid-Schiff, $\times 100$; $g$ and h: hexokinase II, $\times 400$ )

Guzman reported that the higher levels of HKII in HCC were associated with more aggressive histological behavior; however, HK-II expression was not associated with DM. ${ }^{[20]}$ HK-II was expressed in both the HCC tissues and background liver parenchyma of our patients, but its intensity was inversely related to PAS-positivity, being higher in cells with lower glycogen content. Histological examination showed that our HCC patients have less aggressive phenotypes. It is hypothesized that the reduction of glycogen content in HCC may, therefore, be associated with the appearance of Warburg type of glycolysis. Non-invasive monitoring of the glycogen content of the liver might serve as a basis for predicting the development of HCC. Unfortunately, such an approach is currently not available.

In summary, this study described the two patients with HCC and T2DM, both of whom experienced marked changes in glycogen content in HCC tissues and background liver parenchyma. These studies in larger numbers of patients are needed to clarify a possible relationship between the changes in hepatocellular glycogen content and the development of HCC in diabetic patients with steatohepatitis.

\section{Financial support and sponsorship}

Nil.

\section{Conflicts of interest}

There are no conflicts of interest.

\section{REFERENCES}

1. El-Serag HB, Rudolph KL. Hepatocellular carcinoma: epidemiology and molecular carcinogenesis. Gastroenterology 2007;132:2557-76.

2. Donato F, Tagger A, Gelatti U, Parrinello G, Boffettta P, Albertini A,
Decarli A, Trevisi P, Ribero ML, Martelli C, Porru S, Nardi G. Alcohol and hepatocellular carcinoma: the effect of lifetime intake and hepatitis virus infection in men and women. Am J Epidemiol 2002;155:323-31.

3. Starley BQ, Calcagno CJ, Harrison SA. Nonalcoholic fatty liver disease and hepatocellular carcinoma: a weighty connection. Hepatology 2010;51:1820-32.

4. Yang WS, Va P, Bray F, Gao S, Gao J, Li HL, Xiang YB. The role of pre-existing diabetes mellitus on hepatocellular carcinoma occurrence and prognosis: a meta-analysis of prospective cohort studies. PLoS One 2011;6:e27326.

5. Evans RW, Littler TR, Pemberton HS. Glycogen storage in the liver in diabetes mellitus. J Clin Pathol 1955;8:110-3.

6. Stone BG, Van Thiel DH. Diabetes mellitus and the liver. Semin Liver Dis 1985;5:8-28

7. Bannasch P. The cytoplasm of hepatocytes during carcinogenesis. Electron and light microscopical investigations of the nitrosomorpholine-intoxicated rat liver. Rec Res Cancer Res 1968;19:1100.

8. Dombrowski F, Bannasch P, Pfeifer U. Hepatocellular neoplasms induced by low-number pancreatic islet transplants in streptozotocin diabetic rats. Am J Pathol 1997;150:1071-87.

9. Bannasch P, Khoshkhou NI, Hacker HJ, Radaeva S, Mrozek M, Zillmann U, Kopp-Schneider A, Haberkorn U, Elgas M, Tolle T, Roggendorf M, Toshkov I. Synergistic hepatocarcinogenic effect of hepadnaviral infection and dietary aflatoxin B1 in woodchucks. Cancer Res 1995;55:3318-30.

10. Altmann HW. Hepatic neoformations. Pathol Res Pract 1994;190:51377.

11. Su Q, Benner A, Hofmann WJ, Otto G, Pichlmayr R, Bannasch P. Human hepatic preneoplasia: phenotypes and proliferation kinetics of foci and nodules of altered hepatocytes and their relationship to liver cell dysplasia. Virchows Arch 1997;431:391-406.

12. Buchanan TF, Huvos AG. Clear-cell carcinoma of the liver. A clinicopathologic study of 13 patients. Am J Clin Pathol 1974;61:52939.

13. Shi $\mathrm{Y}, \mathrm{Wu} \mathrm{H}, \mathrm{Wu} \mathrm{W}$, Zhang WJ, Yang J, Chen Z. Association between occult hepatitis B infection and the risk of hepatocellular carcinoma: a meta-analysis. Liver Int 2012;32:231-40.

14. Bannasch P. Glycogenotic hepatocellular carcinoma with glycogenground-glass hepatocytes: a heuristically highly relevant phenotype. World J Gastroenterol 2012;18:6701-8.

15. Ribback S, Calvisi DF, Cigliano A, Sailer V, Peters M, Rausch J, Heidecke CD, Birth M, Dombrowski F. Molecular and metabolic changes in human clear cell foci resemble the alterations occurring in rat hepatocarcinogenesis. $J$ Hepatol 2013;58:1147-56.

16. Teng CF, Hsieh WC, Wu HC, Lin YJ, Tsai HW, Huang W, Su IJ. Hepatitis B virus pre-S2 mutant induces aerobic glycolysis 
through mammalian target of rapamycin signal cascade. PLoS One 2015;10:e122373.

17. Bannach P, Klimek F, Mayer D. Early bioenergetic changes in hepatocarcinogenesis: preneoplastic phenotypes mimic responses to insulin and thyroid hormone. J Bioenerg Biomembr 1997;29:303-13.

18. Klimek F, Bannasch P. Isoenzyme shift from glucokinase to hexokinase is not an early but a late event in hepatocarcinogenesis. Carcinogenesis 1993;14:1857-61.
19. Yasuda S, Arii S, Mori A, Isobe N, Yang W, Oe H, Fujimoto A, Yonenaga Y, Sakashita H, Imamura M. Hexokinase II and VEGF expression in liver tumors: correlation with hypoxia-inducible factor 1 alpha and its significance. $J$ Hepatol 2004;40:117-23.

20. Guzman G, Chennuri R, Chan A, Rea B, Quintana A, Patel R, Xu PZ, Xie $\mathrm{H}$, Hay N. Evidence for heightened hexokinase II immunoexpression in hepatocyte dysplasia and hepatocellular carcinoma. Dig Dis Sci 2015;60:420-6. 